\title{
TIC SOBRE GEOLINGUÍSTICA: UM ROBÔ ACIONADO POR TEXTO E VOZ
}

\author{
Prof. Edio Roberto Manfio (Fatec-SP / PPGEL-UEL) \\ Prof. Fábio Carlos Moreno (SENAI-PR / CCE-UEL)
}

\section{RESUMO}

As TICs podem se manifestar nos mais diversos tipos de equipamentos e respectivos suportes e/ou recursos. Nesse contexto, esse trabalho tem por objetivo apresentar uma proposta de uso em espaço educacional para um robô de conversação diferenciado denominado Tical - Tecnologia Interativa Conversacional sobre Assuntos Linguísticos. O robô é programado para responder perguntas sobre Linguística que podem ser feitas tanto pelo teclado alfanumérico quanto por comandos de voz. As repostas são impressas na tela por meio de sua interface e também podem ser ouvidas por meio de voz sintética, tudo operando em Português Brasileiro. O assunto específico sobre o qual ele versa no interior da Linguística é a Geolinguística e, mais especificamente, o moderno Atlas Linguístico do Brasil, publicado em 2014. Essa área temática pode despertar o interesse de alunos, professores e pesquisadores envolvidos em quase todas as categorias educacionais vigentes no Brasil - desde o ensino fundamental até pós-graduação - e o sistema tem potencial de atender a pessoas com necessidades especiais - principalmente no quesito motor.

Palavras-chave: TIC, comandos por voz, robô de conversação, ALiB.

\section{INTRODUÇÃO}

Delimitar o conceito de Tecnologia de Informação e Comunicação (doravante apenas TIC) em uma era em que as tecnologias desenvolvem-se de modo exponencial é uma tarefa bastante complexa. A própria palavra tecnologia, isolada das expressões em que normalmente figura, abarca uma complexidade bastante grande e, no trato cotidiano, a maioria das pessoas tem dificuldade em defini-la. As TICs, portanto, têm sua dimensão semântica mais facilmente delimitável quando é possível determinar a comunidade e a época nas quais elas se manifestam.

Para exemplificar, o telégrafo, obsoleto desde a primeira metade do século XX, constituía-se de uma autêntica TIC para determinadas comunidades. Mais velozes que cartas, sessões telegrafadas proporcionavam tomadas de decisões mais rápidas e, comparativamente, acumulavam mais informações. Uma comunidade outrora fechada, que nessa época passasse a se servir de um aparelho de telégrafo, estreitaria suas relações com outras comunidades e se converteria em um "sistema aberto, dinâmico, urbano" (OLIVEIRA, 2003, p. 112).

Nesse início de século XXI, em que as comunicações são globais, não só em função de um sistema avançado de telefonia fixa e móvel, mas também pela disponibilidade de uma rede mundial de computadores, fala-se muito no conceito de comunidade planetária, 


\section{SEMINÁRIO DE PESQUISA EM CIÊNCIAS HUMANAS - SEPECH \\ Humanidades, Estado e desafios didático-científicos \\ Londrina, 27 a 29 de julho de 2016}

em que as TICs utilizadas avançam para atender às novas demandas dessa moderna comunidade globalizante.

As TICs voltadas à educação e aprendizado tem espaço considerável no conjunto. Além disso, são cada vez mais variadas e manifestam-se nos mais diversos tipos de equipamentos e respectivos suportes e/ou recursos: televisão, cinema, internet, softwares e aplicativos.

De acordo com a Unesco, o que se espera em termos educacionais das TICs é que possam ser operacionalizadas de modo a fazer com que professores e alunos não apenas desenvolvam autonomia de uso no sentido de dominá-las de modo minimamente adequado, mas também que não sejam meros expectadores a ponto de estabelecerem com os conteúdos por ela veiculados uma relação de unilateralidade ou passividade. Nas palavras da Organização, a tecnologia pode - e deve - permitir que docentes e discentes tornem-se

usuários qualificados das tecnologias da informação; pessoas que buscam, analisam e avaliam a informação; solucionadores de problemas e tomadores de decisões; usuários criativos e efetivos de ferramentas de produtividade; comunicadores, colaboradores, editores e produtores; cidadãos informados, responsáveis e que oferecem contribuições (UNESCO, 2008).

O Programa Nacional de Formação Continuada em Tecnologia Educacional ProInfo Integrado (MEC, online, 2016), por exemplo, é destinado à formação para o uso didático-pedagógico das TICs no cotidiano escolar. O Programa articula-se com a distribuição dos equipamentos tecnológicos nas unidades de ensino e também com a disponibilidade de conteúdos e/ou recursos multimídia veiculados por iniciativas educacionais vinculadas ao governo: Portal do Professor, TV Escola, Domínio Público, Banco Internacional de Objetos Educacionais.

Em um segmento mais específico e em franco desenvolvimento, há ainda alguns outros recursos que avançaram muito entre as tecnologias digitais voltadas à aprendizagem como os Sistemas Tutores Inteligentes, os Ambientes Inteligentes de Aprendizagem, a Engenharia de Ontologias e os Robôs de Conversação.

Os Sistemas Tutores Inteligentes (STIs) e os Ambientes Inteligentes de Aprendizagem (AIAs) facilitam, por exemplo, o processo de socialização (REATEGUI et al, 2006), muito importante em ambientes de aprendizagem. A Engenharia de Ontologias que é uma tecnologia relacionada à Web Semântica e vinculada a projetos de ambientes e sistemas educacionais é algo bastante moderno e tem apresentado bons resultados quando da criação de ambientes voltados ao ensino e aprendizado (GLUZ; VICARI, 2010). Os robôs de conversação, por sua vez, foco principal das discussões neste trabalho, embora não tenham sido criados especificamente para educação, podem cumprir este papel de forma bastante eficiente se implementados para tal.

Nesse contexto, esse trabalho tem como finalidade principal apresentar uma proposta de uso em espaço educacional para um robô de conversação diferenciado denominado Tical que, além das funções para as quais foi criado, pode operar também como uma TIC em praticamente todas as modalidades escolares previstas na Constituição brasileira: ensinos fundamental, médio, tecnológico e superior. 


\section{SEMINÁRIO DE PESQUISA EM CIÊNCIAS HUMANAS - SEPECH \\ Humanidades, Estado e desafios didático-científicos \\ Londrina, 27 a 29 de julho de 2016}

\section{ESPECIFICIDADES DE TICAL}

\subsection{Comandos e síntese por voz}

Tical - sigla para Tecnologia Interativa Conversacional sobre Assuntos Linguísticos - é programado para responder perguntas sobre Linguística que podem ser feitas tanto pelo teclado alfanumérico quanto com comandos por voz. As repostas são impressas na tela em sua interface e também podem ser ouvidas por meio de voz sintética, tudo operando em Português Brasileiro.

Note-se que apenas por esses recursos, o aplicativo já pode ser classificado como aqueles que têm potencial de inclusão social, ou seja, caso o usuário tenha problemas de ordem motora, pode fazer as perguntas usando a voz. Se a necessidade especial for visão, conta ainda com as respostas por meio de síntese de voz.

Embora o recurso de comandos por voz não seja novidade há décadas e, de modo bastante pronunciado, tenha se desenvolvido exponencialmente nos últimos dez anos, há ainda relativamente poucos sistemas que operam em português em relação a outros idiomas como inglês, espanhol, francês, italiano, japonês ou mesmo chinês (Mandarim).

$\mathrm{O}$ português está entre as seis línguas mais faladas no mundo. Em alguns datasheets, ora figura em quinta posição, ora em sexta posição. Essa variação ocorre porque, na prática,

não é consensual a real posição do Português Brasileiro entre as diferentes instituições e órgãos que mensuram esses números pois isso depende de uma série de fatores, entre eles, da perspectiva em que se observa o fenômeno. A Ethnologue: Languages of the World, por exemplo, cujo critério não discrimina entre falantes nativos e não nativos, é um desses órgãos que traz o português em sexto lugar (MANFIO, 2016, p. 15)

De qualquer forma, é um dado extremamente relevante quando se trata de implementar um aplicativo, considerando que os usuários normalmente são vulneráveis a quesitos como usabilidade, interface amigável ou ambiência amigável, a facilidade do idioma pode fazer uma grande diferença.

Além disso, esse aspecto do aplicativo Tical colabora diretamente com a preocupação de manter e projetar o idioma junto à Sociedade da Informação (BARBOSA, 2004; WHITMAN ?????) em âmbito mundial, tendo em vista que o português, independentemente de sua variedade dialetal, é falado em vários pontos bastante distintos do globo. Veja-se que, por esse ângulo, qualquer TIC que tenha suporte para o português mesmo que especificamente do Brasil - pode ser utilizada sem maiores problemas em outras comunidades lusófonas do mundo e, não há sobra de dúvidas que a versatilidade e grau de projeção toponímica vão ao encontro do amplo conceito de TIC.

Somando-se a potencial versatilidade relativa ao idioma e, por extensão, essa iminente possibilidade de expansão geográfica à capacidade de inclusão social citada anteriormente, pode-se conseguir resultados interessantes caso receba em sua implementação quesitos para atuar na esfera educacional. 


\section{SEMINÁRIO DE PESQUISA EM CIÊNCIAS HUMANAS - SEPECH \\ Humanidades, Estado e desafios didático-científicos \\ Londrina, 27 a 29 de julho de 2016}

\subsection{Projeção Educacional do Tema}

O assunto sobre o qual Tical versa no interior da Linguística é a Geolinguística e, mais especificamente, o moderno Atlas Linguístico do Brasil (doravante apenas ALiB). O ALiB (CARDOSO et al., 2014a; 2014b) "é uma obra inédita e única na história da Geolinguística brasileira, não só pela abrangência em termos territoriais como também pela acurácia dos dados coletados" (MANFIO, 2016).

O Projeto Atlas Linguístico do Brasil iniciou-se durante o Seminário Caminhos e Perspectivas para a Geolinguística no Brasil realizado na cidade de Salvador, em novembro de 1996. Publicado oficialmente em outubro de 2014, o Atlas apresenta um panorama dos hábitos linguísticos - fônicos, lexicais, gramaticais - de falantes de várias regiões do Brasil e a descrição dessa realidade linguística tem um poder de aplicabilidade imensurável e interessa a todos os brasileiros, mas principalmente aos estudiosos de língua portuguesa (CARDOSO, 1998).

A Geolinguística, portanto, enquanto área temática, pode despertar o interesse de alunos, professores e pesquisadores desde o ensino fundamental até pós-graduação. Isso pode ocorrer porque, primeiro, ela é representada por uma obra abrangente, atual e de grande valor científico para o Brasil: o ALiB. Segundo porque, como aborda fatos linguísticos inerentes a todos os brasileiros e à sua cultura de uma forma geral, é muito comum que os usuários se identifiquem com o conteúdo e explorem o aplicativo de modo mais interessado, comparativamente a alguns assuntos mais abstratos e/ou de pouca aplicabilidade no cotidiano.

As diferentes palavras que representam o mesmo conceito, por exemplo, exploradas por um atlas linguístico, adquirem uma organização bastante diversa daquela estabelecida pelos dicionários. Em outras palavras, não se trata apenas de apresentar sinônimos. Termos como semáforo, sinaleiro e sinal são apresentados no ALiB como variantes lexicais de um mesmo equipamento, ou seja, como ele é chamado em cada uma das regiões do país em que há a variação.

Os mesmos termos, buscados em dicionários da língua portuguesa, embora tenham relação entre si, apresentam acepções múltiplas e são necessárias várias consultas - ao menos uma pra cada termo - para que se possa traçar um mapa mental minimamente adequado das respectivas proximidades semânticas. A título de ilustração, há vinte e cinco acepções diferentes para a palavra sinal no Dicionário Aurélio (NOVO Dicionário, 2010).

De modo similar, as palavras mandioca, macaxeira e aipim, relativas às denominações de uma mesma planta em diferentes regiões do Brasil, também podem ser apreciadas em um mesmo estudo/seção do ALiB. Nos dicionários, no entanto, macaxeira $\mathrm{e}$ aipim remetem à mandioca, mas o inverso não ocorre. É necessário certo grau de inferência por parte do usuário para que este possa visualizar os termos sem hierarquização, ou seja, não há um termo mais importante que outro, e sim, preferências dialetais já identificadas por estudos geolinguísticos.

Note-se que consultas feitas a um dicionário e a um atlas não são excludentes. Pelo contrário, podem ser feitas concomitantemente. Com a ajuda de computadores, os volumes em papel podem ser substituídos por suas versões digitais e a consulta ganha em 


\section{SEMINÁRIO DE PESQUISA EM CIÊNCIAS HUMANAS - SEPECH \\ Humanidades, Estado e desafios didático-científicos \\ Londrina, 27 a 29 de julho de 2016}

velocidade. Para o caso do atlas linguístico, especificamente, o que se propõe aqui é que seja estudado a partir de um robô de conversação, que tem o potencial de tornar o processo de consulta uma prática diferenciada.

Esse fenômeno, por si só, já pode ser investigado como uma transformação de um determinado contexto educacional mediado por TIC, além de também estar alinhado ao desenvolvimento de letramentos digitais, ou seja, é possível aprender novas palavras e contextualizá-las no panorama dialetal brasileiro. Como possibilidade extra, é possível observar em números - por meio dos gráficos e tabelas com dados do ALiB - o modo como essas palavras ocorrem em território nacional.

\subsection{Compatibilidade entre softwares}

Inicialmente o robô foi implementado na linguagem $\mathrm{C}++$, utilizando o Visual Studio 2010 da Microsoft. Posteriormente, foi reescrito também em C\# para gerar compatibilidade com a API - Application Programming Interface ou Interface de Programação de Aplicativos, uma maneira mais rápida de fazê-lo funcionar no WhatsApp.

Com a linguagem C\#, foi possível modificar a interface de Tical preparando para a web. Utilizando de ASP.NET, Tical foi apresentado no III CIDs (MANFIO; MORENO; BARBOSA, 2014) e conseguiu responder a maioria dos questionamentos dos internautas que visitaram a página. Num total de 734 perguntas realizadas, respondeu corretamente 627. Sendo um percentual de $85 \%$ de acertos.

Em termos de Sistema Operacional (doravante SO), Tical opera em praticamente todas nas plataformas Windows 32 e 64 bits. Embora seja também possível, o protótipo ainda não foi testado em Linux ou OS - da Apple. O Windows foi escolhido como plataforma para desenvolvimento e testes do protótipo porque a maior parte dos usuários comuns no mundo a utilizam diariamente - mais de 90 por cento dos equipamentos desktop (NETMARKETSHARE, online, 2016). Outro motivo é que há maior disponibilidade de softwares, ferramentas aplicativos para implementação compatíveis com esse SO. O modo como o banco de dados para teste está organizado tem a ver com os princípios básicos do Processamento de Linguagem Natural e opera sobre tabelas tipo hash ${ }^{1}$.

Este tipo de estrutura de dados - tabela hash - é utilizada em compiladores que por essa razão trabalham muito bem com léxicos (AHO, 1995). No caso deste projeto, auxiliou nas buscas rápidas e eficazes, além da possibilidade das buscas por palavras similares.

O reconhecimento de voz opera a partir do Coruja (LAPS, online, 2016), que além de ser compatível com o SO utilizado, é bastante funcional e apresenta boa acurácia em termos de acerto, considerando usuários dos dois sexos e de faixas etárias diferentes.

\footnotetext{
${ }^{1}$ Hash significa 'picadinho' ou mesmo 'bagunça' e relaciona-se ao método de transformação de chave, conhecido como hashing. Basicamente, é uma estrutura de dados que associa palavras-chave - ou chaves de pesquisa - a elementos correlacionados - ou valores. Tem como vantagem o potencial de realizar uma busca rápida e obter valorer a partir de uma entrada simples como uma palavra (ZIVIANI, 1999).
} 


\section{SEMINÁRIO DE PESQUISA EM CIÊNCIAS HUMANAS - SEPECH \\ Humanidades, Estado e desafios didático-científicos \\ Londrina, 27 a 29 de julho de 2016}

Importante lembrar sobre isso que, muitos sistemas de reconhecimento de voz existentes até o fechamento deste texto, embora bastante eficientes de um modo geral, apresentam

problemas de reconhecimento de alguns grupos de palavras quando da troca de usuários: um adulto por uma criança, um homem por uma mulher. A Figura 1 ilustra esta interação com Tical utilizando o conjunto de ferramentas descritas.

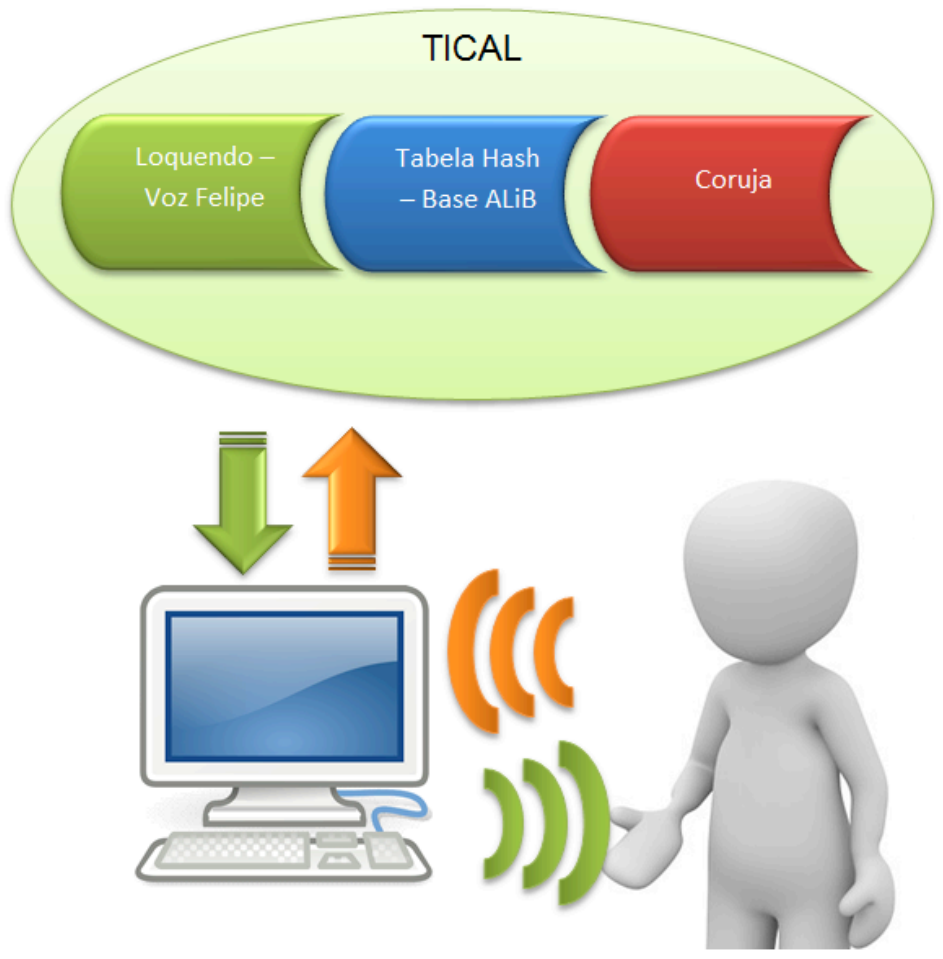

Figura 1 - Tical acionado por voz

Quanto ao recurso de síntese de voz, embora qualquer voz sintética disponível possa ser utilizada desde que o software que a operacionaliza seja compatível com o SO, foi dada a preferência por testá-lo com a voz denominada Felipe (NUANCE, online, 2016) por ser uma das melhores vozes masculinas disponíveis para Português Brasileiro.

Tical opera também por Whatsapp, condição em que qualquer pessoa munida de um celular devidamente conectado a uma operadora, consegue consultar o robô de qualquer lugar do mundo, recurso bastante eficiente a alunos, professores e pesquisadores que desejem saber mais sobre o ALiB (MORENO et al. 2015).

\section{CONSIDERAÇÕES FINAIS}

Tal como comentado anteriormente, o robô de conversação Tical pode, dependendo da aplicação/implementação, ter como foco práticas de formação de professores, práticas de sala de aula da educação básica ou educação superior. De um modo geral, em função dos 


\section{SEMINÁRIO DE PESQUISA EM CIÊNCIAS HUMANAS - SEPECH \\ Humanidades, Estado e desafios didático-científicos \\ Londrina, 27 a 29 de julho de 2016}

recursos que ele já é capaz de disponibilizar nessa sua versão prototipal, pode operar abrangendo processos educacionais de caráter colaborativo, gêneros digitais, inclusão acadêmica, inclusão profissional e relacionar elementos como educação, letramento digital e participação social.

Os recursos presentes em Tical, separadamente não são novidades, em absoluto. Mas a junção desses recursos operando em conjunto e o modo como o fazem é que tornam o protótipo diferenciado: robô de conversação; sobre Geolinguística; em Português Brasileiro; com comandos por voz; com síntese de voz; que opera por Whatsapp; compatível com várias versões do SO mais utilizado no mundo.

Em constante atualização, Tical entra agora em uma nova etapa na qual seu banco de dados para teste será substituído por outro bem mais poderoso: todo o Atlas Linguístico do Paraná (AGUILERA, 1990). A implementação, já em andamento, quando terminada, permitirá que seja testado em condições reais de pesquisa e educação. Nesse estágio, o robô não será mais um protótipo da TIC, e sim, uma TIC com os quesitos necessários para tornar-se operacional.

\section{REFERÊNCIAS}

AGUILERA, Vanderci de Andrade. Atlas Lingüístico do Paraná. 1990. v. 1. Tese (Doutorado em Letras) - Universidade Estadual Paulista Júlio de Mesquita Filho (UNESP), Assis: 1990.

AHO, Alfred V. et. al Compiladores: princípios, técnicas e ferramentas. Tradução Daniel de Ariosto Pinto. Rio de Janeiro: LTC, 1995.

BARBOSA, Cinthyan Renata Sachs Camerlengo de. Técnicas de parsing para gramática livre de contexto lexicalizada da língua Portuguesa. (Doutorado em Engenharia Eletrônica e Computação) - Curso de Engenharia Eletrônica e Computação - Instituto Tecnológico de Aeronáutica. São José dos Campos, 2004. 171 f.

CARDOSO, Suzana Alice Marcelino da Silva et al. Atlas Linguístico do Brasil: Introdução. Vol. 1. Londrina: Eduel, 2014a.

CARDOSO, Suzana Alice Marcelino da Silva et al. Atlas Linguístico do Brasil: Cartas Linguísticas I. Vol. 2. Londrina: Eduel, 2014b.

CARDOSO, Suzana Alice Marcelino. O Atlas Linguístico do Brasil: um projeto nacional. In: AGUILERA, Vanderci de Andrade (org.). A Geolingüistica no Brasil: caminhos e perspectivas. Londrina: EDUEL, 1998.

GLUZ, João Carlos; VICARI, Rosa Maria. MILOS: Infraestrutura de Agentes para Suporte a Objetos de Aprendizagem OBAA. Anais... SBIE 2010. 


\section{SEMINÁRIO DE PESQUISA EM CIÊNCIAS HUMANAS - SEPECH \\ Humanidades, Estado e desafios didático-científicos \\ Londrina, 27 a 29 de julho de 2016}

LAPS - Laboratório de Processamento de Sinais. Disponível em: $<$ http://www.laps.ufpa.br/falabrasil/descricao.php>. Acesso em: 04 abr. 2016.

MANFIO, Edio Roberto. Avaliação de dispositivos acionados por voz e texto para o Português Brasileiro. 2016. 121 f. Tese (Doutorado em Estudos da Linguagem) Universidade Estadual de Londrina, Londrina, 2016.

MANFIO, Edio Roberto; MORENO, Fabio Carlos; BARBOSA, Cinthyan Renata Sachs Camerlengo de. Professor Tical: Robô de Conversação sobre Dialetologia e Geossociolinguística. In: III CIDS - CONGRESSO INTERNACIONAL DE DIALETOLOGIA E SOCIOLINGUÍSTICA - Variação, Atitudes linguísticas e Ensino. Londrina, UEL. Caderno de Resumos. ISBN: 978857846297 0. Londrina, 2014. p. 48.

MEC - Ministério da Educação. ProInfo Integrado. Disponível em: $<$ http://portal.mec.gov.br/component/content/article?id=13156:proinfo-integrado $>$. Acesso em: 18 abr. 2016.

MORENO, Fábio Carlos et al. Tical: Chatbot sobre o Atlas Linguístico do Brasil no WhatsApp. In: XXVI SIMPÓSIO BRASILEIRO DE INFORMÁTICA NA EDUCAÇÃO SBIE (CBIE - V Congresso Brasileiro de Informática na Educação \& LACLO - X Conferência Latino-Americana de Objetos e Tecnologias de Aprendizagem). Maceió, Alagoas. Anais... ISSN: 2316 6533. Maceió, 2015.

NETMARKETSHARE - Market Share Statistics for Internet Technologies. Operating Systems - Desktop share. Disponível em: $<$ http://netmarketshare.com/>. Acesso em: 24 abr. 2016.

NOVO Dicionário Aurélio da Língua Portuguesa. 5 ed. Versão 7.0. 1 CD. São Paulo: Positivo, 2010.

NUANCE - Loquendo. Disponível em: <http://www.nuance.com/for-business/bysolution/customer-service-solutions/solutions-services/inbound-solutions/loquendo-smallbusiness-bundle/interactive-tts-demo/index.htm>. Acesso em: 18 abr. 2016.

OLIVEIRA, Jayr Figueiredo de. T.I.C - Tecnologias da Informação e da Comunicação. São Paulo: Érica, 2003.

REATEGUI, Eliseo Berni et al. Kurrupako: um agente animado sócio afetivo para ambientes de aprendizagem. Novas Tecnologias CINTED-UFRGS na Educação. V. 4 No 1, Julho, 2006.

UNESCO. Padrões de competência em TIC para professores: Diretrizes de implementação. VERSÃO 1.0. Paris: Unesco, 2008. 


\section{SEMINÁRIO DE PESQUISA EM CIÊNCIAS HUMANAS - SEPECH}

Humanidades, Estado e desafios didático-científicos

Londrina, 27 a 29 de julho de 2016

ZIVIANI, Nivio. Projeto de algoritmos: com implementação em Pascal e C. 4. ed. São Paulo: Pioneira, 1999. 